Full length article

\title{
Angiogenic peptide nanofibers repair cardiac tissue defect after myocardial infarction
}

\author{
Abdul Jalil Rufaihah ${ }^{\mathrm{a}, 1}$, I. Ceren Yasa ${ }^{\mathrm{b}, 1}$, Vaibavi Srirangam Ramanujam ${ }^{\mathrm{a}}$, \\ Suganya Cheyyatraivendran Arularasu ${ }^{\mathrm{a}}$, Theo Kofidis ${ }^{\mathrm{a}, \mathrm{c}, *}$, Mustafa O. Guler ${ }^{\mathrm{b}, \mathrm{d}, *}$, Ayse B. Tekinay ${ }^{\mathrm{b}, \mathrm{e}, *}$ \\ a Department of Surgery, Yong Loo Lin School of Medicine, National University of Singapore, Singapore \\ b Institute of Materials Science and Nanotechnology, National Nanotechnology Research Center (UNAM), Bilkent University, Ankara 06800, Turkey \\ ${ }^{\mathrm{c}}$ Dept of Cardiac, Thoracic \& Vascular Surgery, National University Heart Centre Singapore, National University Health System, Singapore \\ ${ }^{\mathrm{d}}$ Institute for Molecular Engineering, University of Chicago, Chicago, IL 60637, USA \\ ${ }^{\mathrm{e}}$ Neuroscience Graduate Program, Bilkent University, Ankara 06800, Turkey
}

\section{A R T I C L E I N F O}

\section{Article history:}

Received 6 October 2016

Received in revised form 1 June 2017

Accepted 5 June 2017

Available online 13 June 2017

\section{Keywords:}

Myocardial infarction

Peptide nanofibers

Neovascularization

Cardiomyocyte

VEGF

\begin{abstract}
A B S T R A C T
Myocardial infarction remains one of the top leading causes of death in the world and the damage sustained in the heart eventually develops into heart failure. Limited conventional treatment options due to the inability of the myocardium to regenerate after injury and shortage of organ donors require the development of alternative therapies to repair the damaged myocardium. Current efforts in repairing damage after myocardial infarction concentrates on using biologically derived molecules such as growth factors or stem cells, which carry risks of serious side effects including the formation of teratomas. Here, we demonstrate that synthetic glycosaminoglycan (GAG) mimetic peptide nanofiber scaffolds induce neovascularization in cardiovascular tissue after myocardial infarction, without the addition of any biologically derived factors or stem cells. When the GAG mimetic nanofiber gels were injected in the infarct site of rodent myocardial infarct model, increased VEGF-A expression and recruitment of vascular cells was observed. This was accompanied with significant degree of neovascularization and better cardiac performance when compared to the control saline group. The results demonstrate the potential of future clinical applications of these bioactive peptide nanofibers as a promising strategy for cardiovascular repair.
\end{abstract}

\section{Statement of Significance}

We present a synthetic bioactive peptide nanofiber system can enhance cardiac function and enhance cardiovascular regeneration after myocardial infarction (MI) without the addition of growth factors, stem cells or other biologically derived molecules. Current state of the art in cardiac repair after MI utilize at least one of the above mentioned biologically derived molecules, thus our approach is ground-breaking for cardiovascular therapy after MI. In this work, we showed that synthetic glycosaminoglycan (GAG) mimetic peptide nanofiber scaffolds induce neovascularization and cardiomyocyte differentiation for the regeneration of cardiovascular tissue after myocardial infarction in a rat infarct model. When the peptide nanofiber gels were injected in infarct site at rodent myocardial infarct model, recruitment of vascular cells was observed, neovascularization was significantly induced and cardiac performance was improved. These results demonstrate the potential of future clinical applications of these bioactive peptide nanofibers as a promising strategy for cardiovascular repair.

(c) 2017 Acta Materialia Inc. Published by Elsevier Ltd. All rights reserved.

\footnotetext{
* Corresponding authors at: Department of Surgery, Yong Loo Lin School of Medicine, National University of Singapore, Singapore (T. Kofidis). Institute for Molecular Engineering, University of Chicago, Chicago, IL 60637, USA (M.O. Guler). Institute of Materials Science and Nanotechnology, UNAM-National Nanotechnology Research Center, Bilkent University, Ankara 06800, Turkey (A.B. Tekinay).

E-mail addresses: surtk@nus.edu.sg (T. Kofidis), mguler@uchicago.edu (M.O. Guler), atekinay@bilkent.edu.tr (A.B. Tekinay).

1 These authors contributed equally.
}

\section{Introduction}

Cardiovascular diseases constitute one of the major life threatening diseases and are among the leading causes of morbidity and mortality worldwide [1]. The prevailing cause of heart failure is the death of heart muscle tissue. This irreplaceable cardiomyocyte loss caused by arrested blood and oxygen flow to the heart is detrimen- 
tal as it leads to pathological remodeling, reduced myocardial function and inevitable progression to heart failure [2]. Current treatments for salvaging the jeopardized myocardium include pharmacological therapy and percutaneous coronary intervention or coronary artery bypass surgery. The limited efficiency of current medical treatments might result in final stage heart failure, and such heart failure patients require heart transplantation, which has limited availability, or the support of ventricular assisted devices, which have limited efficacy [3]. These limitations plummet the patient's odds of survival and have led to the development of novel therapeutic strategies such as regenerative medicine and tissue engineering approaches for the repair of damaged myocardial tissues.

Induction of angiogenesis is a vital mechanism that may alleviate heart dysfunction after myocardial infarction (MI). Increased vascularization and oxygen supply to the affected ischemic area can reduce the degree of cardiomyocyte apoptosis and fibrosis $[4,5]$. It is also essential to prevent the transition of infarction to heart failure by providing long term left ventricular remodeling. Pro-vascularization signals including biomolecules such as extracellular matrix elements (e.g. collagen, elastin, laminin and fibronectin), growth factors (e.g. VEGF and FGF2) and GAGs (e.g. heparan sulfate and chondroitin sulfate), make up the structural framework that regulates the behavior of vascular cells (i.e. endothelial and smooth muscle cells) in order to establish stable and functional vascular networks [6].

To date, several strategies have been tested including using cytokines to modulate inflammation, introducing angiogenic growth factors and transplantation of stem cells within various matrices [7-9]. Previous studies also demonstrated the potential of using heparin to deliver growth factors. Heparin preserves growth factors in their active form by protecting them from proteolysis, and enhances the growth factors' affinity to their respective receptors, enabling consistent release of growth factors for an extended period and optimizing their local concentration [1016]. The ability of heparin to bind to several angiogenesis promoting growth factors, such as VEGF and FGF2, chemokines and cell adhesion molecules via specific electrostatic interactions mediated by their heparin binding domains or sulfated sequences have previously been identified. This binding boosts cell signaling, inducing the formation of new blood vessels [17,18]. On the other hand, the use of heparin in tissue engineering applications could trigger immune reactions due to its animal origin [19].

Supramolecular scaffolds formed by self-assembling peptides could address unmet needs of cardiac regenerative medicine by providing a structural and functional recapitulation of native tissue elements. Their biocompatibility and versatility for attachment of discrete bioactive chemical groups make peptide based scaffolds suitable for various tissue engineering applications [20-22]. Molecular stacking of these motifs through non-covalent interactions gives rise to the formation of high-aspect-ratio nanofibers at physiological conditions. These nanofibrous scaffolds can have the advantage of slow degradation, hypo-immunogenicity, and suitability for sustained release of specific growth factors immobilized through covalent bonding. Recently, multidomain VEGF mimetic peptides have been shown to promote an increase in the microvessel density in an in vivo model in which hydrogels were subcutaneously injected to the animals [23]. In another study, nanofibers presenting VEGF-mimetic peptide at high density were shown to induce phosphorylation of VEGF receptors and promote proangiogenic behavior in endothelial cells [24]. In a model of acute myocardial infarction, significant preservation of hemodynamic functions was demonstrated after injection of heparin binding self-assembling peptide nanofibers, which were capable of binding to VEGF and bFGF [25]. Other studies also used injectable in situ self-assembling peptide gels to recruit endogenous endothelial and smooth muscle cells and to stimulate angiogenesis by slow release of angiogenic factors [26,27].

Recently, we have developed a GAG mimetic peptide nanofiber scaffold that interacts with endogenous growth factors and induces angiogenesis without the addition of external growth factors or other supplements $[6,28]$. Through an innovative design, the GAG mimetic peptide amphiphiles (PA) were decorated with a sulfonate, hydroxyl and carboxylic acid groups in order to mimic heparan sulfate glycosaminoglycans, which are fundamental constituents of the extracellular matrices of many tissues and known to regulate growth factor binding and distribution [29]. In addition to VEGF, GAG mimetic nanofibers were demonstrated to bind to other angiogenesis related growth factors including hepatocyte growth factor (HGF) and fibroblast growth factor-2 (FGF2) $[6,28]$.

Here, we show that the injection of this previously described angiogenic GAG mimetic peptide nanofibers led to better cardiac function via preservation of more cardiac muscle and formation of new blood vessels after MI in a rat cardiac infarct model. Cardiac functional parameters were monitored through echocardiography and hemodynamics and cellular level remodeling was assessed through histological and immunofluorescence assessment. In addition to in vivo MI model, adhesion and differentiation of cardiomyoblast cells were studied in vitro.

\section{Materials and methods}

\subsection{Materials}

All 9-fluorenylmethoxycarbonyl (Fmoc) and tertbutoxycarbonyl (Boc) protected amino acids, lauric acid, [4-[ $\alpha-(2$ 0,40-dimethoxyphenyl) Fmoc-aminomethyl] phenoxy] acetamidonorleucyl-MBHA resin (Rink amide MBHA resin) and 2(1H-benzotriazol-1-yl)-1,1,3,3-tetramethyluronium hexafluorophosphate (HBTU) and diisopropylethylamine (DIEA) were purchased from NovaBiochem, Merck and ABCR. The other chemicals for peptide synthesis were analytical grade and purchased from Fisher, Merck, Alfa Aesar, or Sigma Aldrich. All other materials used in this study were purchased from Sigma-Aldrich, Invitrogen, BioRad, Fisher and Merck.

\subsection{Synthesis and characterization of peptide amphiphiles}

PA molecules were synthesized by using solid phase peptide synthesis method with Rink amide MBHA resin. For coupling of amino acids, 1.95 equivalents of HBTU, 3 equivalents of DIEA and 1 equivalent of starting resin were used with 2 equivalents of amino acid in $10 \mathrm{~mL}$ of dimethylformamide (DMF). Coupling of each amino acid takes $2 \mathrm{~h}$ and Fmoc removal was performed with $20 \%$ (v/v) piperidine/dimethylformamide solution for $20 \mathrm{~min}$. Lauric acid addition was performed similarly to amino acid coupling except that coupling time was $4 \mathrm{~h}$. In order to acetylate the free amine groups after each coupling step, $10 \%(\mathrm{v} / \mathrm{v})$ acetic anhydride-DMF solution was used after each coupling. Dichloromethane (DCM) and DMF were used for washing steps. The $p$ sulfobenzoic acid addition to $\varepsilon$-amine of lysine was done after cleavage of Mtt protecting group of Fmoc-Lys(Mtt)-OH residue with $5 \%$ of cleavage cocktail in DCM 3 times for 5 min. Peptide cleavage from the resin and deprotections were carried out with 95\% cleavage cocktail (95:2.5:2.5 trifluoroacetic acid (TFA): triisopropylsilane (TIS):water) for $2 \mathrm{~h}$ at room temperature. Excess TFA was removed by rotary evaporation. Remaining PA solution was precipitated in ice-cold diethyl ether overnight at $-20^{\circ} \mathrm{C}$. Centrifugation was used to collect the precipitate and ultrapure water was used to dissolve the pellet. The solution was frozen at $-80^{\circ} \mathrm{C}$ and 
then lyophilized. The lyophilized product was characterized by Agilent 6530 quadrupole time of flight (Q-TOF) mass spectrometry with electrospray ionization (ESI) source equipped with reversephase analytical high performance liquid chromatography (HPLC) with Zorbax Extend-C18 $2.1 \times 50 \mathrm{~mm}$ column for basic conditions and Zorbax SB-C8 $4.6 \times 100 \mathrm{~mm}$ column for acidic conditions. To purify the PA molecules and remove residual TFA, preparative HPLC system (Agilent 1200 series) was used for negatively charged PAs and $0.1 \mathrm{M} \mathrm{HCl}$ was used for positively charged PAs. Dialysis was used as a further purification method for the positively charged PAs. After purification, PA molecules were lyophilized.

\subsection{Nanofiber formation and characterization}

Solutions were prepared by dissolving PAs in sterile double distilled water, and their $\mathrm{pH}$ values were adjusted to 7.4. GAG mimetic nanofibers were formed by mixing two PAs with different molar ratios to have different charge combinations. To form GAG mimetic nanofibers at pH 7.4, GAG-PA and K-PA molecules were mixed at 1:2 molar ratio, respectively. Control nanofiber group was prepared by mixing at 1:2 molar ratio of K-PA and E-PA, respectively.

\subsubsection{Circular dichroism analysis}

CD (JASCO J815 CD) was used to analyze secondary structures of PAs. GAG-PA and K-PA as GAG mimetic nanofiber and E-PA and K$P A$ as control nanofiber group were mixed at a concentration of $2 \times 10^{-4} \mathrm{M}$. Secondary structures of individual PA were also analyzed at $2 \times 10^{-4} \mathrm{M}$ concentration. Scanning was done between $190 \mathrm{~nm}$ and $300 \mathrm{~nm}$ using a digital integration time of $1 \mathrm{~s}$, a bandwidth of $1 \mathrm{~nm}$ and with standard sensitivity. Molar ellipticity was calculated with the data obtained from measurements.

\subsubsection{Mechanical characterization of the PA hydrogels}

An oscillatory rheometer (Anton Paar Physica RM301) operating with a $25 \mathrm{~mm}$ parallel plate configuration at $25^{\circ} \mathrm{C}$ was used to investigate the mechanical properties of GAG-PA/K-PA gel. $10 \mathrm{mM}$ GAG-PA and K-PA with a total volume of $250 \mu \mathrm{L}$ were loaded on the center of the plate and measurement was done with $0.5 \mathrm{~mm}$ gap distance, $100-0.1 \mathrm{rad} / \mathrm{s}$ angular frequency and $0.1 \%$ shear strain. Similarly, E-PA with K-PA at $10 \mathrm{mM}$ concentration with a total volume of $250 \mu \mathrm{L}$ was prepared to analyze mechanical properties of resulting gel.

\subsubsection{Scanning electron microscopy and transmission electron microscopy imaging}

Morphological properties of the GAG mimetic nanofibers and control nanofibers were observed with scanning electron microscopy (SEM, FEI Quanta 200 FEG). GAG mimetic nanofiber was formed by mixing $10 \mathrm{mM}$ GAG-PA and K-PA and control nanofibers were formed by mixing $10 \mathrm{mM}$ K-PA and E-PA, allowing gel formation for $10 \mathrm{~min}$ followed by serial ethanol dehydration steps. After gradual ethanol dehydration, hydrogels were dried by using critical point dryer (Tousimis, Autosamdri-815B, Series C critical point dryer) and coated with $5 \mathrm{~nm} \mathrm{Au} /$ Pd before imaging.

Nanofibers were imaged by transmission electron microscopy (TEM) (FEI Tecnai G2 F30 TEM). For sample analysis, 1 mM GAGPA was mixed with $2 \mathrm{mM}$ K-PA (Control nanofibers were prepared by mixing $1 \mathrm{mM}$ K-PA with $2 \mathrm{mM}$ E-PA in equal volumes) in equal volumes on a 200-mesh carbon TEM grid for 1 min followed by $2 \mathrm{wt} \%$ uranyl acetate staining for $40 \mathrm{~s}$ and drying under flow hood. TEM images were acquired at $300 \mathrm{kV}$.

\subsection{Myocardial infarction model and GAG mimetic nanofiber treatment}

All animal procedures were approved by the National University of Singapore, Institutional Animal Care, and Use Committee. Male Wistar rats (250-350 g) were anaesthetized using inhalation of $2 \%$ isoflurane and oxygen. Electrocardiography (ECG) was done 1 week before surgery to monitor the heart function. The chest cavity was opened through mid-thoracotomy. The pericardium was opened and the heart was exposed for sham groups $(n=15)$. For the saline $(n=15)$, GAG mimetic nanofiber treated groups $(n=15)$ and control nanofiber treated group $(n=15)$, myocardial infarction was created by ligation of the left descending coronary artery with a 7-0 suture. Ischemia assessment was done by the immediate observation of myocardial blanching and alterations in the ECG. Saline or PA solutions (GAG mimetic nanofiber as a mixture of GAG-PA and K-PA, control nanofiber as a mixture of E-PA and K-PA) (total volume $=100 \mu \mathrm{L}$ ) were injected at 4 different sites ( $25 \mu \mathrm{L}$ per site). After treatment, the chests were closed followed by closing the muscle layer and skin layer. ECG was done to monitor the post-surgery heart function. The rats were frequently monitored and allowed to recover in a small animal intensive care unit.

\subsection{Echocardiography and hemodynamic measurement}

Echocardiography was performed at day 0 and day 31 postoperatively and measured by using the Vivid 6 Dimension ultrasound system (General Electric Vingmed, Horten, Norway) equipped with the broadband $10 \mathrm{~S}$ transducer. Following anesthesia with isoflurane (5\%) and oxygen (95\%), EchoPac ${ }^{\mathrm{TM}}$ software was used to measure the parameters such as Ejection Fraction (EF), Fractional Area Change (FAC), Left-Ventricular (LV) internal dimension in systole and diastole, End-Systolic Volume (ESV) and End-Diastolic Volume (EDV).

The hemodynamic analysis was performed at 4 weeks post operatively immediately prior to sacrifice using a pressurevolume catheter (SPR-838NR, Millar Instruments, Houston, TX). The catheter was inserted into the apex of the LV. The catheter was stabilized for $15 \mathrm{~min}$ and then pressure-volume wave forms were recorded using a multiple recording systems. Hemodynamic data was analyzed using Lab chart 6.2 software (AD Instruments, Australia). The hemodynamic analysis was performed and interpreted by researchers blinded to the treatment arms.

\subsection{Histological analysis}

The rats were sacrificed after the final echocardiography and the hearts were excised and cut into two equal transverse slices $(n=6)$. The lower slice was embedded in OCT while the upper slice was paraffin embedded. Heart sections of $5 \mu \mathrm{m}$ thickness on glass slides. The sections were first deparaffinized in Bond ${ }^{\mathrm{TM}}$ Dewax Solution and then rehydrated through $100 \%$ ethanol to $1 \times$ Bond $^{\mathrm{TM}}$ Wash Solution. They were stained with either Masson Trichrome or Hematoxylin and Eosin according to the manufacturer's protocol. The hematoxylin and eosin stained heart sections were analyzed to measure the degree of infarct size and area and to investigate the general tissue architecture. The LV slices from each heart were digitized using (Leica) and then analyzed by Image J software (NIH, Bethesda, Maryland) in a blinded manner. Briefly, the length of the entire free wall and the portion occupied by the infarct scar (both obtained at the midwall level) were measured, and the degree of the infarct size was estimated as the ratio between infarct scar length and length of the entire free wall and expressed as a percentage of the entire free wall. For infarct area measurement, both the infarct area and the total LV area were manually traced from 
the digitalized image and calculated using Image J. The infarct size, expressed as a percentage was calculated by dividing the infarct area to total LV area and multiplying by 100 .

\subsection{Capillary density and VEGF expression analysis}

The heart sections were stained with rat endothelial cell antigen-1 (RECA-1) (Serotec, Puchheim, Germany) and alphasmooth muscle actin (alpha-SMA) (Sigma, Missouri, USA) to analyze the arterial density. Briefly, the frozen slides were fixed in chilled $10 \%$ neutral buffered saline for $10 \mathrm{~min}$ at room temperature. After washing with $1 \mathrm{X}$ TBS-T, the slides were blocked with $10 \%$ goat serum for $30 \mathrm{~min}$. The primary antibodies, RECA-1 (1:50) and alpha-SMA (1:100) were incubated overnight at $4{ }^{\circ} \mathrm{C}$. After washing, secondary antibodies, Alexa-fluor 594 (1:500) and 488 (1:1000) were applied. The nuclei were then counterstained with Vectashield ${ }^{\mathrm{TM}}$ Hard Set mounting medium with DAPI. The RECA-1 and alpha-SMA positive vessels in 5 randomly selected fields were evaluated in the infarct zones and peri-infarct zones. The capillary and arterial densities were quantified in a blinded manner and the data were presented as the mean number of vessels per $200 \times$ magnification field. VEGF (Abcam, USA) was stained using deparaffinized tissues that were treated with the same way as mentioned above at a working dilution factor of 1:100.

\subsection{Cell culture and maintenance}

H9C2 cells derived from embryonic rat ventricle were a kind gift from Gazi University, Ankara, Turkey. Cells were cultured in a humidified, $37{ }^{\circ} \mathrm{C}, 5 \% \mathrm{CO}_{2}$ incubator using $75 \mathrm{~cm}^{2}$ polystyrene cell culture tissue flasks containing High Glucose Dulbecco's modified Eagle's medium (DMEM) supplemented with 15\% (v/v) fetal bovine serum (FBS), 1\% (v/v) penicillin/streptomycin (P/S) and $4 \mathrm{mM} \mathrm{L-}$ glutamine. Passaging of cells was carried out at cell confluency between 50 and $60 \%$, using trypsin/EDTA. Cells were diluted 1:4 for subculturing. Differentiation induction was carried out after cells became $80 \%$ confluent by adding high glucose DMEM supplemented with $1 \%(\mathrm{v} / \mathrm{v})$ FBS, $1 \%(\mathrm{v} / \mathrm{v})$ penicillin/streptomycin and $10 \mathrm{nM}$ retinoic acid (RA, Sigma-Aldrich). In all experiments, the medium was changed in every 2 days.

\subsection{In vitro cell culture studies}

In vitro tests were carried out on GAG mimetic nanofiber or Control nanofiber coated tissue culture plates and cover slips unless otherwise mentioned. The coating was done by mixing PAs in equal volume at $1 \mathrm{mM}$ GAG-PA and $2 \mathrm{mM} \mathrm{K-PA}$ concentration after $\mathrm{pH}$ adjustment and sonication. Similarly, control nanofibers were prepared by mixing $1 \mathrm{mM} \mathrm{K}-\mathrm{PA}$ and $2 \mathrm{mM}$ E-PA in equal volume. Before coating process, solutions were sterilized under UV for at least $1 \mathrm{~h}$. Gel formation was achieved at $37^{\circ} \mathrm{C}$ for $30 \mathrm{~min}$ and drying was performed under laminar flow hood overnight. Before experiments, dried plates were further sterilized under UV light for $1 \mathrm{~h}$ and washed with $1 \times$ PBS to remove unbound nanofibers.

Cell viability on the surface of nanofibers was tested with Alamar Blue ${ }^{\circledR}$ viability assay. In this experiment, 3 different charges were tested and negatively, neutral and positively charged combinations were formed by mixing GAG-PA $(1 \mathrm{mM})$ and K-PA at varying molar ratios $1: 2,1: 3$ and $1: 4$, respectively. H9C2 cells were seeded in 96 -well plates at a density of $5 \times 103$ cells/well. After $24 \mathrm{~h}$ of standard incubation, Alamar Blue ${ }^{\circledR}$ reagent was diluted 1:10 with serum-free medium and replaced with standard medium. After subsequent $4 \mathrm{~h}$ of incubation, absorbance was measured using microplate reader at $570 \mathrm{~nm}$ and $600 \mathrm{~nm}$ background. We continued with -1 charge combination (1:2 ratios) for further experiments.
For cell adhesion experiments, cells were incubated for $1 \mathrm{~h}$ in serum free DMEM medium supplemented with $4 \mathrm{mg} / \mathrm{mL}$ Bovine Serum Albumin (BSA) and $50 \mathrm{mg} / \mathrm{mL}$ cyclohexamide at standard culture conditions before seeding. After $1 \mathrm{~h}$, cells were removed from tissue culture plate by trypsinization and seeded onto the coated 96 -well plates at a density of $5 \times 103$ cells/well. After $2 \mathrm{~h}$ of incubation in serum-free medium at standard culture conditions, Calcein AM (Invitrogen) staining $(2 \mu \mathrm{M})$ was performed for 40 min according to the manufacturer's instructions. Cell adhesion was quantified directly by counting the number of cells using Image $\mathrm{J}(\mathrm{NIH})$ program from the images taken with a Zeiss Axioscope fluorescent microscope. Images were taken from 4 to 5 different locations per well, and the experiment was carried out with $\mathrm{n}=4$. Results were then normalized to TCP.

The proliferation of cells on GAG mimetic nanofiber coating was assessed using BrdU assay after $72 \mathrm{~h}$. Cells were seeded onto PA coated wells (1:2 molar ratio) and tissue culture plates at a density of $3 \times 103$ cells/well. Cells were incubated in standard cell culture conditions for $72 \mathrm{~h} .2 \mathrm{~h}$ prior to the experiment, cell medium was replaced with $10 \mu \mathrm{M}$ BrdU labeling solution-containing standard maintenance medium. At the end of incubation, BrdU incorporation assay was performed according to manufacturer's instructions. Briefly, cells were fixed with FixDenat for $30 \mathrm{~min}$ and anti BrdU-POD solution was added into wells. Following $90 \mathrm{~min}$ of incubation and tapping, substrate solution was added into wells and proliferation rates of the cells were quantified by measuring absorbance (370 nm, with $492 \mathrm{~nm}$ reference wavelength) with a microplate reader (Spectramax M5, Molecular Devices).

\subsection{Gene expression analysis}

Quantitative RT-PCR (qRT-PCR) was used for gene expression analysis. Total RNA was isolated from cells, which were incubated in differentiation medium for 7-10 days, using TRIzol (Invitrogen) according to manufacturer's instructions. Nanodrop 2000 (Thermo Scientific) was used to assess yield and purity of extracted RNA. Primer sequences were designed using Primer 3 software. The reaction efficiencies for each primer set were evaluated with a standard curve using 2-fold serial dilutions of total RNA. cDNA synthesis from RNA and qRT-PCR were performed using SuperScript III Platinum SYBR Green One-Step qRT-PCR Kit (Invitrogen) according to manufacturer's instructions. Ventricular myosin light chain-2 (Mlc-2v) and Myogenin genes' expression patterns were analyzed at day 0,3 and 4 . Primer sequences are shown in Table S1. Reaction conditions were briefly as follows: $55^{\circ} \mathrm{C}$ for $5 \mathrm{~min}, 95^{\circ} \mathrm{C}$ for $5 \mathrm{~min}$, 40 cycles of $95^{\circ} \mathrm{C}$ for $15 \mathrm{~s}, 60^{\circ} \mathrm{C}$ for $30 \mathrm{~s}$, and $40^{\circ} \mathrm{C}$ for $1 \mathrm{~min}$, followed by a melting curve to confirm product specificity. For analysis of the expression data, primary gene expression data were normalized by the expression level of GAPDH. A comparative $\mathrm{Ct}$ method was used to analyze the results. Gene expression was normalized to GAPDH and uncoated surfaces. For VEGF and Ang- 1 tissue expression, RNA was extracted from the heart tissues using the RNeasy Fibrous Tissue Kit. cDNA synthesis was performed using QuantiTect ${ }^{\circledR}$ Reverse Transcription Kit (QIAGEN, Hilden, Germany). Real Time PCR was done using BioRad CFX Thermal Cycler to check on the expression of VEGF and Ang-1. The Taqman VEGF and Ang-1 primers were purchased from Life Technologies, USA.

\subsection{Immunocytochemistry}

Cardiac Troponin $\mathrm{T}$ staining was utilized as a marker of cardiomyocyte differentiation. H9C2 myoblast cells were seeded onto PA coated surfaces and glass surface $(15 \mathrm{~mm})$ at a density of $1.5 \times 104$ cells/well. Differentiation was induced after reaching confluency. The medium was changed every day. For immunocytochemistry, cells were fixed in $4 \%(\mathrm{v} / \mathrm{v})$ paraformaldehyde/PBS for 
$10 \mathrm{~min}$ and permeabilized in $0.1 \%(\mathrm{v} / \mathrm{v})$ Triton $\mathrm{X}-100$ for $15 \mathrm{~min}$. To reduce nonspecific binding, samples were incubated with $3 \%(\mathrm{w} / \mathrm{v})$ bovine serum albumin/PBS blocking reagent for $2 \mathrm{~h}$ and treated with 1:200 diluted Cardiac Troponin T primary antibody (Ms. Ab33589) overnight at $4{ }^{\circ} \mathrm{C}$, and were incubated with Alexa Fluor 488 goat anti-mouse secondary antibody at 1:300 dilution for $1 \mathrm{~h}$ at room temperature. Extensive washing with $1 \times$ PBS was performed between each step. All samples were counterstained with $1 \mu \mathrm{M}$ TO-PRO-3 (Invitrogen) and 1:500 diluted phalloidine in $1 \times$ PBS for $20 \mathrm{~min}$ at room temperature and mounted with Prolong Gold Antifade Reagent (Invitrogen). Samples were imaged by using a confocal microscope (Zeiss LSM510).

\subsection{Statistical analysis}

In vivo data are presented as the mean \pm standard deviation and $\mathrm{n}=15$ for all groups. One-way analysis of variance (ANOVA) followed by Tukey-HSD post-hoc multiple comparison tests was utilized for comparison of multiple groups using Graphpad prism software. The difference was considered statistically significant at a p-value of $<0.05$.

The quantitative in vitro results are presented as a mean \pm standard error of the mean (SEM). Statistical analysis was carried out by means of one-way analysis of variance (ANOVA) with Tukey posttest and student $t$-test unless otherwise mentioned. A pvalue of less than 0.05 was considered statistically significant. All the experiments were independently repeated 3 times.

\section{Results}

\subsection{Formation and characterization of self-assembled peptide nanofibers}

Modulation of cardiovascular cell fate through the extracellular matrix (ECM) mimicking smart biomaterials is an emerging strategy for developing efficient regenerative cardiovascular therapies. Self-assembling PA molecules decorated with biologically active groups that mimic the structure of heparan sulfate were synthesized and utilized to generate a nanofibrous microenvironment that can mimic the structural and functional aspects of the native myocardial extracellular matrix. Since angiogenesis is one of the crucial factors for the functional restoration of the myocardium, GAG mimetic peptide nanofibers were assessed for their ability in protecting the ischemic myocardium due to their growth factor binding capacities and angiogenic properties. The chemical structures of GAG peptide amphiphile, Lauryl-VVAGEGD$\mathrm{K}(p$-sulfobenzoyl)-S-Am (GAG-PA) and oppositely charged Lauryl-VVAGK-Am (K-PA) are shown in Fig. 1. To assess the effect of the nanofibrous morphology, compared to the bioactivity caused by mimicking heparan sulfate, we used non-bioactive nanofibers (Control nanofibers) composed of E-PA and K-PA (Fig. 1). The PA molecules were synthesized by using Fmoc solid phase peptide synthesis, purified by preparative HPLC and analyzed by LC-MS (Fig. S1). The self-assembly of the PAs into nanofibers was triggered by mixing oppositely charged GAG-PA and K-PA as GAG mimetic nanofiber group and E-PA with K-PA as Control nanofiber group. Their abilities to form extended structures were analyzed using circular dichroism (CD). The CD spectra of the PAs demonstrated an ordered $\beta$-sheet secondary structure as the major structural component of the assembled nanofibers (Fig. 1B). Oscillatory rheology measurements, which were performed to analyze the mechanical properties of the peptide hydrogels formed by the nanofibers, showed that the hydrogels exhibited storage moduli between 5 and $6 \mathrm{kPa}$ and loss moduli between 300 and $400 \mathrm{~Pa}$ at $10 \mathrm{mM}$ concentration (Fig. 1C).
SEM micrographs showed that the self-assembly of PAs generated porous nanofibrous networks, similar to native ECM (Figs. 1D and S2). TEM images revealed that individual nanofibers formed by self-assembly of oppositely charged PAs were uniform in diameter, which was $\sim 7.5 \mathrm{~nm}$ (Figs. $1 \mathrm{E}$ and S2).

\subsection{Intramyocardial injection of GAG mimetic bioactive peptide nanofiber improved cardiac function post-MI}

In order to assess the effect of GAG mimetic peptide nanofibers on cardiac function post-MI, GAG mimetic or Control nanofibers were injected intramyocardially to the infarct site in rat myocardial infarction model. Echocardiography was used to assess the cardiac function before and after formation of infarct and injection. 30 days post-treatment echocardiography analysis showed that the GAG mimetic nanofiber treated group attenuated left ventricular (LV) remodeling, which is essential to prevent heart failure. Ejection fraction (EF) was $37.28 \pm 10.32 \%$ in the saline group, compared to $71.82 \pm 12.56 \%$ in the GAG mimetic nanofiber treated group. The GAG mimetic nanofiber treated group also showed improvement in fractional area change (FAC) when compared to the saline group. FAC was $41.86 \pm 7.75 \%$ in the saline group and $58.08 \pm 5.13 \%$ in the GAG mimetic nanofiber treated group. The left ventricle internal dimension during diastole (LVIDd) was $9.78 \pm 0.17 \mathrm{~mm}$ in the saline group versus $8.51 \pm 0.31 \mathrm{~mm}$ in the GAG mimetic nanofiber treated group. The left ventricle internal dimension during systole (LVIDS) was $6.91 \pm 0.27 \mathrm{~mm}$ in the saline treated group versus $5.46 \pm 0.53 \mathrm{~mm}$ in the GAG mimetic nanofiber treated group (Fig. 2). GAG mimetic nanofiber treated group also displayed improved end-systolic volume (ESV) and end-diastolic volume (EDV) with a value of $0.17 \pm 0.05 \mathrm{~mL}$ and $0.62 \pm 0.06 \mathrm{~mL}$, respectively. For left ventricular posterior wall at systole (LVPWs) and diastole (LVPWd), the value of $2.17 \pm 0.62 \mathrm{~mm}$ and $1.63 \pm 0.60 \mathrm{~mm}$ was observed respectively. A significant difference was found when results were compared with saline treated groups. The control nanofiber treated group also showed significantly improved cardiac performance because of partial bioactivity due to chemically functional groups (Fig. 2).

\subsection{GAG mimetic bioactive peptide nanofiber treatment resulted in significant improvement in cardiac output, LV pressure, and contractility}

The hemodynamic analysis was carried out in all four groups (sham, saline and Control nanofiber and GAG mimetic nanofiber treated group) and the data is shown in Table 1. No difference was observed in body weight and heart rate at 30 days posttreatment between all four groups. GAG mimetic nanofiber injected group and control nanofiber group showed statistically significant increase in contractility index, cardiac output and mean LV pressure when compared to saline treated group ( $\mathrm{p}<0.05)$.

\subsection{Bioactive GAG mimetic nanofiber hydrogel injection preserved cardiac muscle and prevented infarct expansion}

At 4 weeks post-treatment, cross-sections at the mid papillary muscle level showed transmural infarctions in both saline and peptide nanofiber treated groups. Semi quantitative analysis demonstrated that the infarct size and the infarct area were smaller in the GAG mimetic nanofiber treated group $(43 \pm 6.04$ and $23 \pm 5.21$, respectively) compared to the saline treated group $(62 \pm 7.43$ and $41 \pm 5.12$, respectively) and Control nanofiber treated group ( $51 \pm 8.26$ and $37 \pm 4.78$, respectively) (Figs. 3 and S7). The differences between GAG mimetic nanofiber and control groups were statistically significant. A higher degree of surviving cardiomyocyte tissues in the peri-infarct segment was observed 

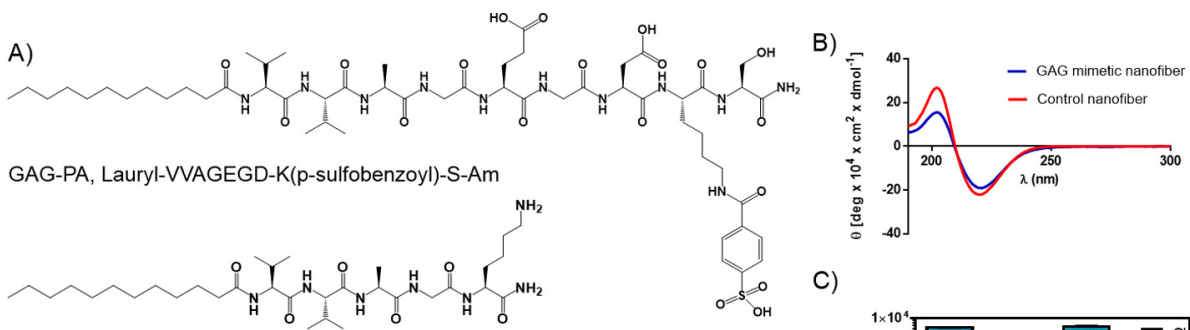

C)
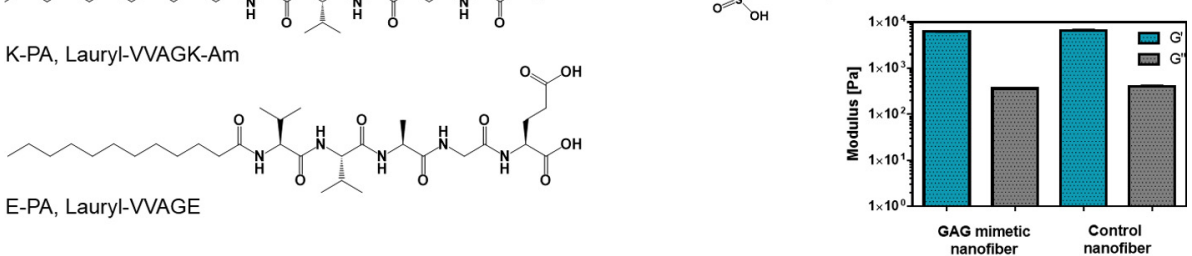

D)
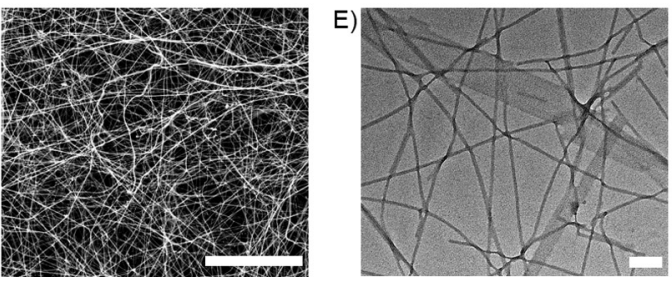

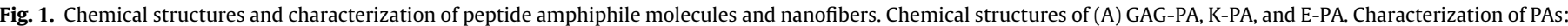

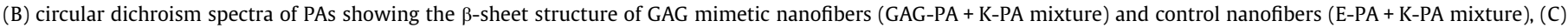

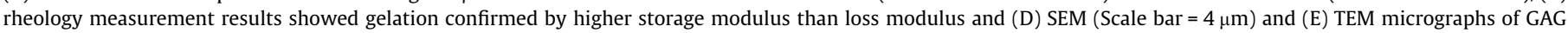
mimetic nanofibers. Micrographs revealed the nanofibers forming a fibrous network that mimic the native nanofibrous ECM architecture $($ Scale bar $=100$ nm).

A)

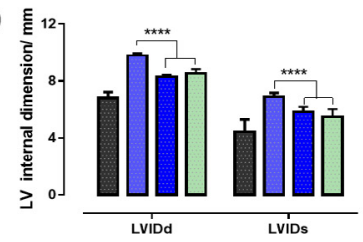

C)

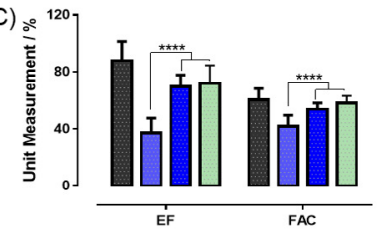

E)
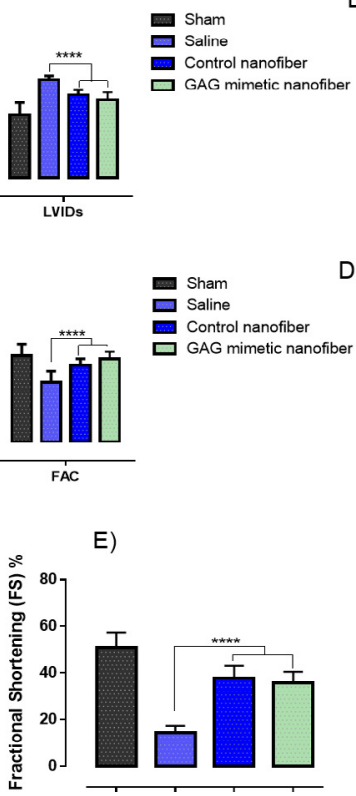

B)
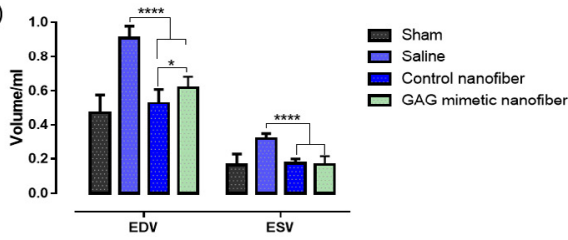

D)

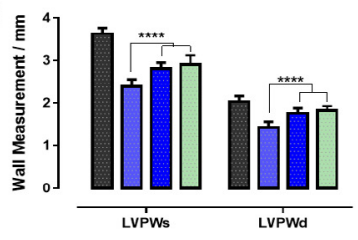

Sham

Control nanofiber

GAG mimetic nanofiber

Fig. 2. Injection of GAG mimetic bioactive peptide nanofiber improved cardiac function at 30 days after MI. Echocardiography analysis at 30 days post-treatment revealed that GAG mimetic nanofiber treated group resulted in better preservation of left ventricular function in comparison to saline treated group. (A) Left ventricular internal dimension at systole (LVIDs) and diastole (LVIDd), (B) end diastolic volume (EDV) and end systolic volume (ESV), (C) ejection fraction (EF) and fractional area change (FAC), (D) left ventricular posterior wall at systole (LVPWs) and diastole (LVPWd). (E) Hydrogel injection significantly enhanced the\% Fractional shortening (FS). Data are means \pm SD ( $\mathrm{n}=15$ per group). ( $\mathrm{p}<0.05$ and ${ }^{*+*+*} \mathrm{p}<0.0001$ compared to saline treated the group as determined by one-way ANOVA and Tukey's comparison test.)

in the GAG mimetic nanofiber and control nanofiber treated groups resulting in increased wall thickness when compared to the saline treated group. In addition, Masson's trichrome staining of the myocardial tissues demonstrated a smaller degree of fibrosis throughout the left ventricle of GAG mimetic nanofiber treated group compared to saline and Control nanofiber treated groups. Pink muscle fibers can be distinguished from blue stained ECM (Fig. 3).

\subsection{Bioactive GAG mimetic peptide nanofiber treatment promoted arteriogenesis after MI}

The GAG mimetic nanofiber treatment resulted in a significantly higher number of stained capillaries compared to saline and Control nanofiber groups in both infarct and peri-infarct areas (Fig. 4A). GAG mimetic nanofiber hydrogel injected group showed a 2.7-fold increase in the number of smooth muscle actin (SMA) 
Table 1

GAG mimetic nanofiber treatment showed improvement in cardiac output, LV pressure, and contractility. ${ }^{*} \mathrm{p}<0.05$ versus saline treated group.

\begin{tabular}{|c|c|c|c|c|}
\hline & Sham & Saline & Control nanofiber group & GAG mimetic nanofiber group \\
\hline Body Weight (g) & $507 \pm 33.21$ & $462 \pm 35.52$ & $476 \pm 32.54$ & $502 \pm 31.68$ \\
\hline Heart rate (bpm) & $183.2 \pm 40.05$ & $171.3 \pm 53$ & $180.67 \pm 37.7$ & $190.2 \pm 12.35$ \\
\hline Contractility Index $(1 / S)$ & $84 \pm 4.6$ & $61.2 \pm 3.7$ & $75.21 \pm 4.1^{*}$ & $79.5 \pm 3.9^{*}$ \\
\hline Cardiac Output & $40.2 \pm 13.8$ & $28.6 \pm 10.5$ & $44.35 \pm 7.13^{*}$ & $51.4 \pm 6.3^{*}$ \\
\hline Mean LV Pressure & $75.4 \pm 9.2$ & $50.8 \pm 7.6$ & $61.7 \pm 4.8^{*}$ & $66.3 \pm 7.5^{*}$ \\
\hline Maximum positive $\mathrm{dp} / \mathrm{dt}$ & $3071 \pm 323.6$ & $1832.2 \pm 256.3$ & $2264 \pm 303.5^{*}$ & $2511 \pm 307.1^{*}$ \\
\hline Maximum negative $\mathrm{dp} / \mathrm{dt}$ & $-2440 \pm 507.4$ & $-1529 \pm 299.1$ & $-1856 \pm 424.1^{*}$ & $-2071 \pm 275.5^{*}$ \\
\hline
\end{tabular}
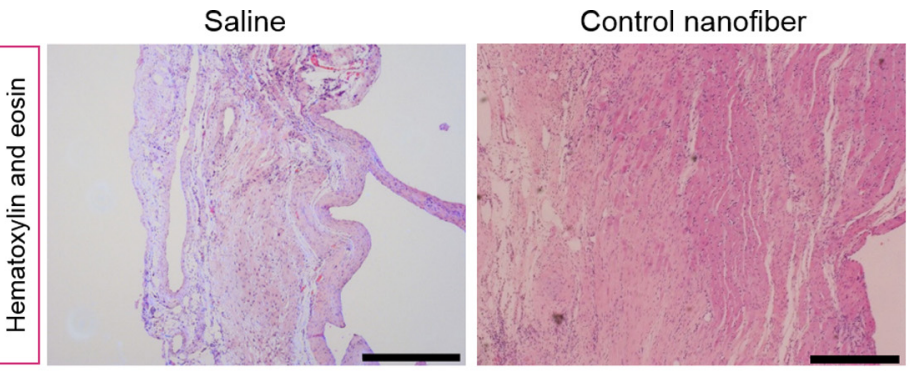

GAG mimetic nanofiber
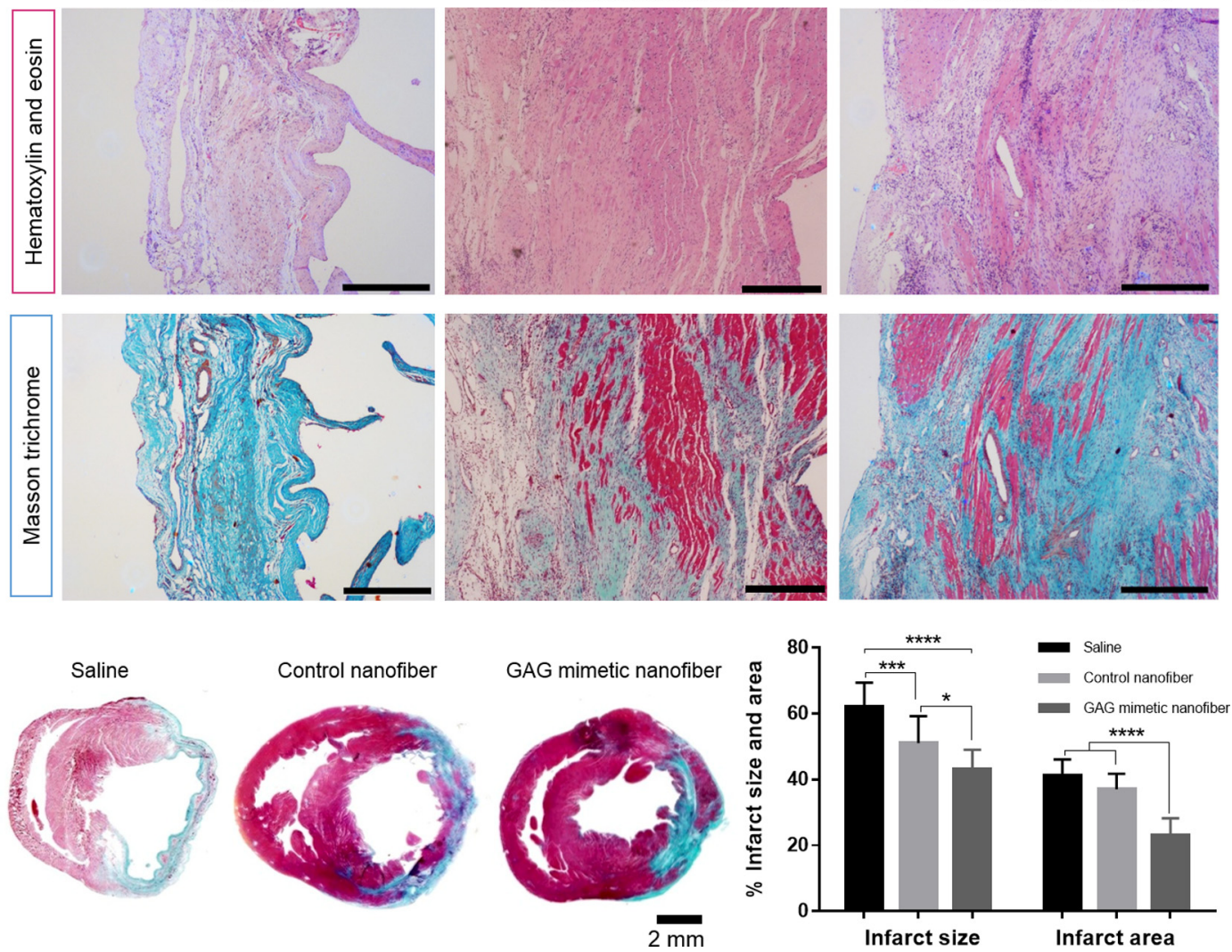

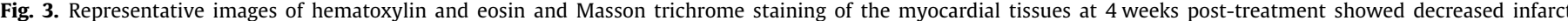

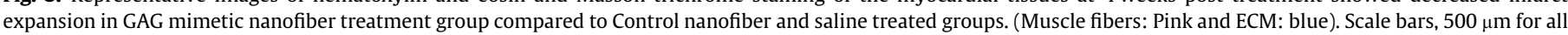

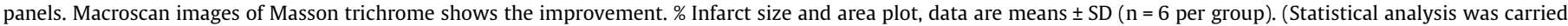
out by one-way ANOVA and Tukey's comparison test, where ${ }^{*} p<0.05,{ }^{* * *} p<0.001$ and ${ }^{* * * *} p<0.0001$ ).

positive vessels and 1.6-fold increase of rat endothelial cell antigen-1 (RECA-1) positive vessels in the infarct area when compared to the saline treated group (Fig. 4B). Also, GAG mimetic nanofiber group showed a 4-fold increase of SMA and 1.9-fold increase for RECA-1 in comparison to Control peptide group. Similarly, in the peri-infarct area, GAG mimetic nanofiber treatment resulted in an approximately 2.3 -fold increase of SMA positive vessels and a 1.8-fold increase of RECA-1 positive vessels when compared to the saline treated group (Fig. 4C) whereas there is the 3.5fold difference in SMA and the 1.57-fold difference in RECA-1 positive vessels compared to Control nanofiber group. These results showed that GAG mimetic nanofiber hydrogel increased arteriogenesis in both infarct and peri-infarct area, significantly.

In addition to RECA-1 and SMA staining, we also investigated gene expression of VEGF-A and Angiopoietin-1 (Ang-1) both of which have important roles in angiogenesis and vascular development. Results showed that there is a 12.3 -fold increase in the expression of VEGF-A in the GAG mimetic nanofiber treated group when normalized to sham. There is 3.6 and 6.1-fold increase in saline and control nanofiber groups, respectively, yet the difference between these groups and GAG mimetic nanofiber group is statistically significant. In terms of Ang-1 expression, similar to VEGF-A expression, there is a 6.02-fold increase in GAG mimetic nanofiber group, which is significantly different than the control groups (Figs. 5D and S6).

Notably, VEGF staining in tissue sections demonstrated the enhanced level and localization of VEGF in both infarct and periinfarct area for GAG mimetic nanofiber treated groups compared to saline treated, and Control nanofiber treated groups (Fig. 5).

\subsection{GAG mimetic peptide nanofibers promoted adhesion and proliferation of cardiomyocytes in vitro}

In order to assess the effect of GAG mimetic nanofibers on the cellular behavior of $\mathrm{H} 9 \mathrm{C} 2$ myoblasts, derived from rat myocardia, was investigated by culturing these cells on peptide nanofiber 

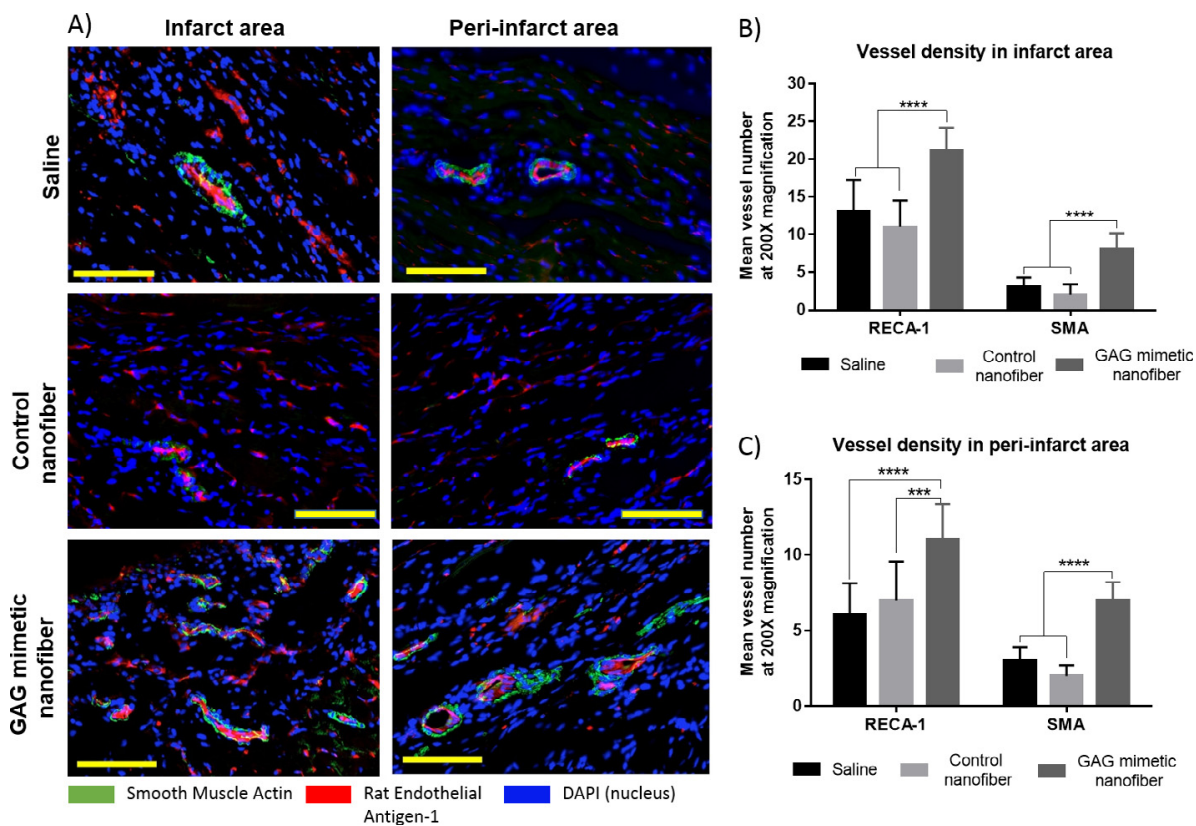

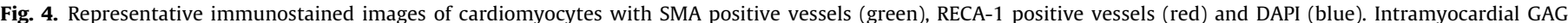

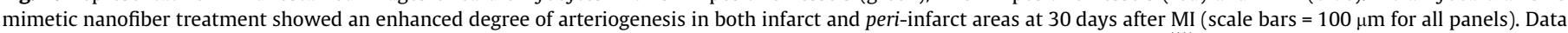
are means \pm SD ( $n=6$ per group). (Statistical analysis was carried out by one-way ANOVA and Tukey's comparison test, where ${ }^{* * * *} p<0.0001$ ).

A) Saline

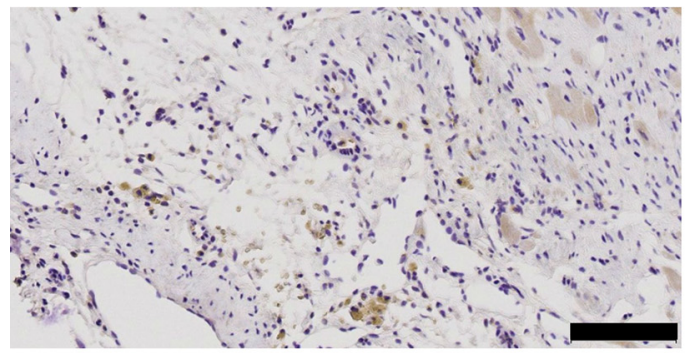

C) GAG mimetic nanofiber

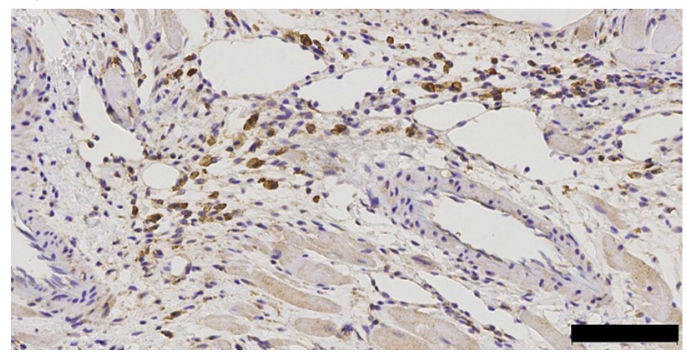

B) Control nanofiber

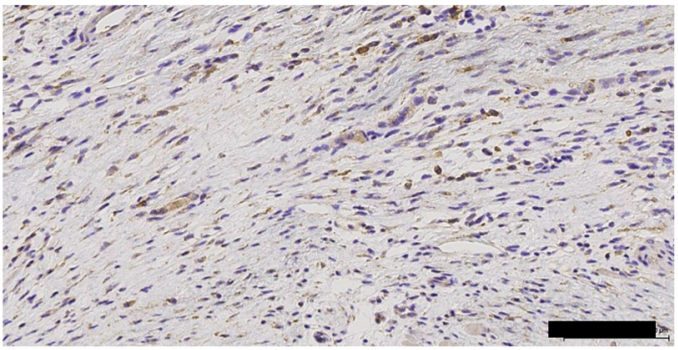

D)

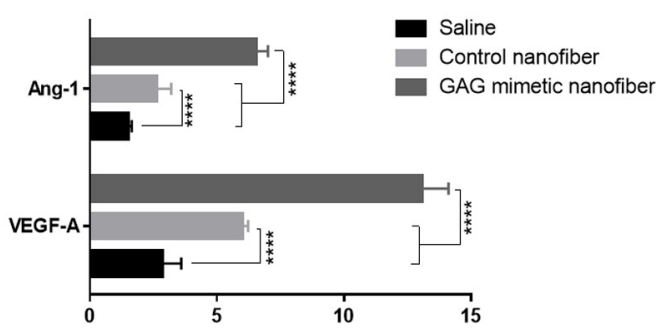

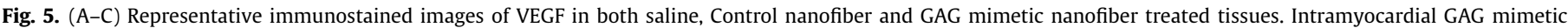

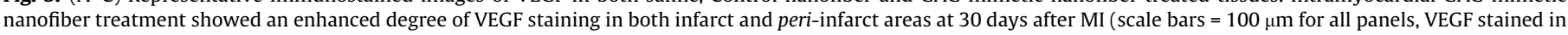

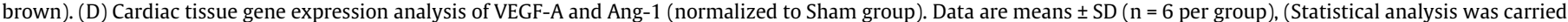
out by one-way ANOVA and Tukey's comparison test, where ${ }^{* * *} p<0.0001$ ).

coated surfaces. To investigate the effect of the total charge of the system on cellular viability, GAG-PA and K-PA molecules were mixed in different molar ratios to display positive, neutral and negative final charges on different wells. Viability of H9C2 cells was analyzed by Alamar Blue assay after culturing on GAG mimetic nanofibers for $24 \mathrm{~h}$, and the results showed that peptide nanofibers did not alter the viability of the cells compared to tissue culture plate (TCP), and GAG/K-PA system is biocompatible with H9C2 cells at all three charge combinations (Fig. 6B). Investigation of cellular morphology with an optical microscope showed that native cell morphology of $\mathrm{H} 9 \mathrm{C} 2$ cells was preserved on PA coated surfaces. In further experiments, molar ratios of mixtures were adjusted to yield a system with a net negative charge, matching the system utilized in our previous study on peptide-induced angiogenesis [6].

We also investigated the initial adhesion behavior of $\mathrm{H} 9 \mathrm{C} 2$ cells on GAG mimetic nanofibers in the presence of bovine serum albumin (BSA) and the translation inhibitor cyclohexamide, which minimizes the interference of endogenous proteins with the adhesion process. After $2 \mathrm{~h}$ of incubation, Calcein AM staining and quantita- 

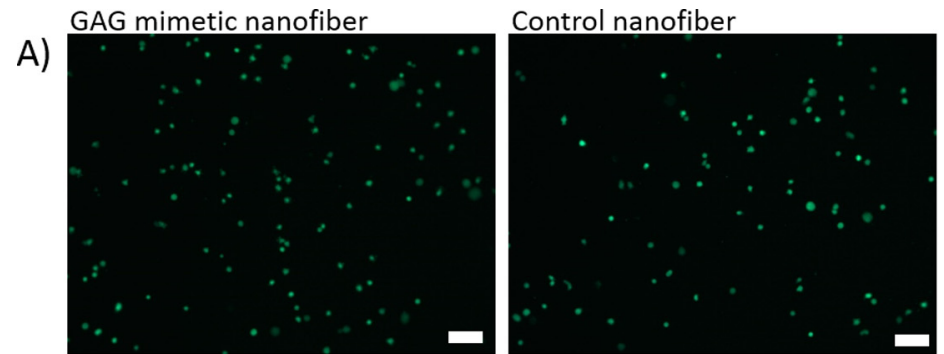

B)

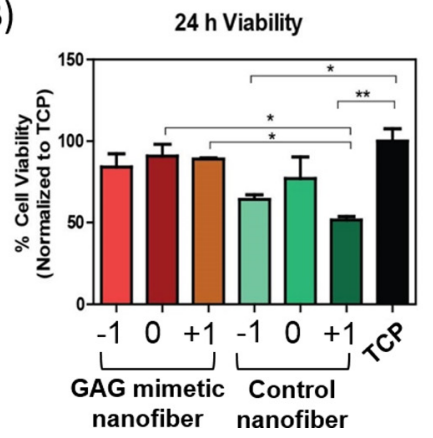

C)

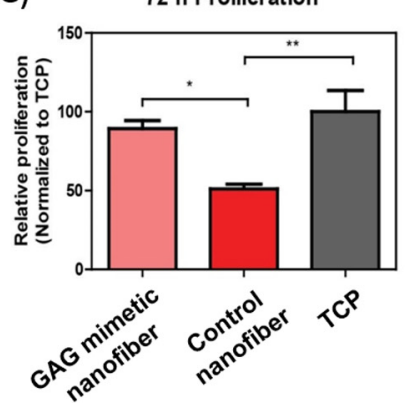

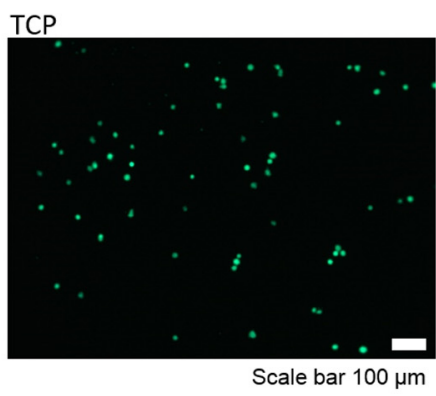

D)

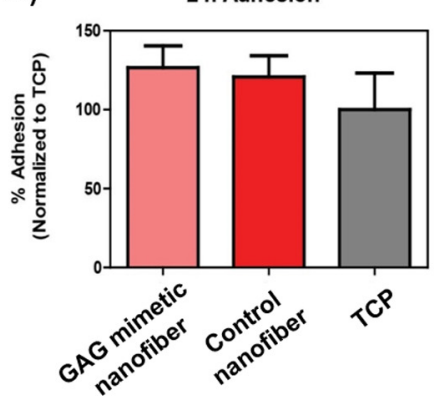

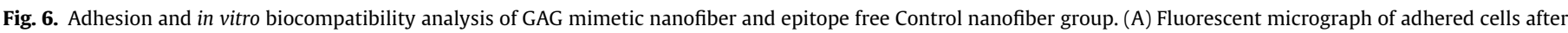

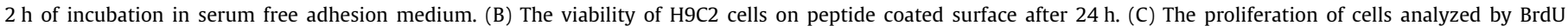
incorporation, (D) Quantitative analysis of initial $2 \mathrm{~h}$ adhesion of cells to surfaces. Data are means \pm SEM $\left({ }^{*} \mathrm{p}<0.05\right)$.

tive data derived from the staining results demonstrated that cells adhered to the GAG mimetic nanofiber coated surface slightly more than uncoated plates (Fig. 6A, D). The proliferation of H9C2 cells on GAG mimetic nanofibers was slightly less than these on TCP, but the difference between the groups was not statistically significant (Fig. 6C), as analyzed by BrdU assay. Control nanofibers used as an epitope-free control group for the GAG mimetic nanofibers did not support the growth and proliferation of cells in vitro (Fig. 6B, C). Therefore, we did not include the epitope-free control group in remaining in vitro experiments.

Effects of peptide nanofibers on the upregulation of the expression of specific cardiac marker genes were analyzed to understand the commitment of progenitor cells into cardiomyocyte lineage [30-32]. The H9C2 cells seeded on GAG mimetic nanofibers showed higher expression of Mlc-2v, a cardiac specific marker [32], than the cells grown on TCP at day 7. Expression started earlier in cells cultured on peptide nanofibers compared to cells cultured on TCP. We also analyzed the gene expression level at day 10 and observed increased expression of Mlc- $2 \mathrm{v}$ on TCP, which shows delayed differentiation of cells on TCP surfaces compared to the GAG mimetic nanofibers (Fig. S3). There was no difference in the expression of the skeletal muscle marker myogenin when the experimental groups were compared (Fig. S3B).

We also investigated the expression of cardiac troponin T (cTnT) protein, which an important cardiac-specific protein and plays a role in cardiac muscle contraction and relaxation [33]. H9C2 cells cultured in growth medium does not exhibit cTnT staining although they fuse with each other which is a typical myoblastic behavior after a certain time of culture (Fig. S4C). However, after the cells were cultivated in differentiation medium for 10 days, cTnT protein expression was observed on both GAG mimetic nanofiber coated surfaces and TCP, and there was no difference between the groups (Fig. S4A and B). Cardiomyocytes on GAG mimetic nanofibers also exhibited sarcomeric organization, observed through phalloidin staining. Likewise, SEM micrographs of cells after 10 days showed the cardiomyocyte-like morphology of cells and further confirmed the absence of long skeletal myotubes (Fig. S5).

\section{Discussion}

One of the major goals of cardiac tissue engineering is to create a favorable microenvironment for cells in ischemic regions, in order to support the cells mechanically as well as guide them biochemically by resembling the native extracellular niche [26,34]. Previous studies elaborated the structural resemblance of peptide nanofibers with collagenous proteins found in the extracellular matrix of many tissues such as collagen I, collagen III and fibrillin whose diameters vary from 10 to $100 \mathrm{~nm}$ [35].

In this study, we demonstrated the potential of GAG mimetic nanofibers in improving heart function by limiting the degree of cardiac fibrosis and preventing negative remodeling in rodent MI model as well as supporting the survival of cardiomyocytes. These nanofibers exhibited $\beta$-sheet morphology, and electron microscopy imaging showed that individual nanofibers formed a nanofiber network that structurally resembles morphology of native ECM by providing mechanical support and instructive cues for cells. The baseline elastic modulus for normal heart muscle was previously shown to be around $18 \pm 2 \mathrm{kPa}$ and infarcted animals receiving no treatment had stiffer tissue due to fibrosis [36]. Peptide nanofibers in the range of 5-10 kPa can withstand the mechanical cycling since they are mechanically compliant with the native tissue and breakdown of the gels during contraction and relaxation is not possible as in the case of hydrogels with low mechanical strength.

Sonnenberg et al. recently used decellularized ECM-derived platform with sulfated glycosaminoglycan content to deliver HGF-1 into rat MI model and demonstrated improved fractional area change and vascularization [37]. Despite its promise and good results, harvesting enough quantity of autologous graft tissue without compromising the donor-site is limited. In addition, although allografts may eliminate such issue, they possess the risk of severe immune response and have integration problems with native tissue compared to autologous grafts [38].

On the other hand, synthetic biologically active peptide nanofibers could be more advantageous in providing similar signals for tissue regeneration due to their very low risk of immune response 
and availability in high quantity. To this end, intramyocardial injection of bioactive GAG mimetic nanofibers resulted in improved cardiac function and enhanced angiogenesis in the infarcted left ventricle. Specifically, treatment with hydrogels showed $69 \%$ improvement in ejection fraction and $35.9 \%$ improvement in fractional shortening.

Interestingly, the positive effects seen after treatment with bioactive GAG nanofibers on the cardiac function was also observed to a certain degree with the control nanofibers. The favorable effects of the control nanofiber treatment could have been due to the mechanical support and structural reinforcement provided by the nanofiber in stabilizing the infarct wall and maintaining the wall thickness. It was previously reported that passive structural enhancement alone cannot provide full therapeutic benefit as a combination of both physical and biological activity are critical [42]. Hence, it is possible that that the functional improvement observed in this study may be a short term response.

On the other hand, increased angiogenesis via upregulation of VEGF and Ang-1 post-MI by GAG mimetic nanofiber treatment compared to control nanofiber group indicated that GAG mimetic nanofiber treatment could be more advantageous in the long run if they are able to sustain the degree of mature vasculature formation. This needs to be addressed further in a long term study of MI models. In addition, a higher degree of surviving cardiomyocyte tissues in the infarct area in the GAG mimetic nanofiber treated group could result in increased wall thickness compared to saline treatment, which alters the surrounding tissue properties and reduces the wall stress. Less wall stress results in reduced after load and end systolic volume, which is likely because there is significant difference in end LV diastolic volume and end systolic volume between saline and nanofiber treated groups. This decrease in LV wall stress is also thought to protect the vulnerable myocardium from stress induced apoptosis and infarct expansion, thus preventing pathologic LV remodeling and decline in cardiac function [43].

It is important to stress that in addition to increasing only the volume of an area similarly to other injectable gels, angiogenic bioactivity of GAG mimetic nanofiber hydrogels is critical in inducing angiogenesis, which ensures a steady supply of oxygen and nutrients to the ischemic area. These peptide nanofibers were recently used to transplant pancreatic islets and shown to improve both viabilities of islets and number of intraomental vessels in diabetic rats [39]. Similarly, in this work, we observed improved cardiomyocyte protection with reduced degree of fibrosis and a significant increase in mature blood vessel formation.

In a previous study, Guo et al. showed improved cardiac function after delivering VEGF with self-assembling peptides [27]. Strikingly, in the present study, we observed same therapeutic effects without any additional exogenous angiogenic growth factors. VEGF and Ang-1 genes are two of many that are turned on to regulate blood vessel growth, and we observed the significantly high level of endogenous VEGF-A and Ang-1 expression in GAG mimetic nanofiber treated animals. This is also supported with the histological staining that shows VEGF localization in infarct and the peri-infarct area is higher in the GAG mimetic nanofiber treated group compared to Control nanofiber and saline treated ones. This confirms that the GAG mimetic nanofibers created a supportive microenvironment by both increasing expression and localization of endogenous growth factors in the infarct and periinfarct regions of the ischemic myocardium and promote recruitment, retention, and maturation of vascular cells.

Immunostaining results also showed a higher degree of arteriogenesis in animals receiving GAG mimetic nanofiber treatment, which implied that the scaffold was able to recruit smooth muscle cells in addition to endothelial cells, to form stable and functional vascular networks (Fig. 4). Newly formed vessels help the restoration of blood flow to prevent loss of cardiomyocytes and enhance cardiac performance, which is in good agreement with the Echo results.

Survival of residual cardiomyocytes could be also supported by increased expression of Ang-1. Ang-1 is known to be a critical glycoprotein that activates prosurvival pathways by binding to integrin receptors of muscle cells and promotes survival [40]. Increased expression of Ang-1 in GAG mimetic nanofiber treated group could be the reason of the prevention of cardiac myocyte loss and retaining of contractility relative to the controls along with its role in the angiogenesis. Also, increased VEGF expression and localization in the ischemic area might contribute to the activation and migration of cardiac stem cell population to the affected area to repair infarction [41]. Overall, GAG mimetic nanofibers enabled cells to restore cardiac function and structure.

Some of the limitations in assessing the data of this study include the use of an acute MI model whereby the treatment is performed 30 min after the infarction was initiated. Acute MI models are relevant to only a subgroup of patients in clinics since the majority of the patients are chronic in nature. The work should be also extended to chronic models in the future. In addition, the period of investigation was 4 weeks and this turned out to be insufficient to differentiate the full effect of the GAG mimetic and control nanofiber treatment. The data, however, confirmed the positive results of other studies on the use of hydrogels in MI models. While we saw the potential of GAG mimetic peptide nanofiber in converting cardiomyoblasts to cardiomyocytes in vitro with the model cell line, we did not observe the creation of new cardiac muscle in the infarcted LV in this short term study of an acute model. A chronic model and/or a longer term study of acute model would be more appropriate in assessing this capability of GAG mimetic nanofibers in vivo.

\section{Conclusion}

In summary, we present the efficacy and safety of the injectable self-assembled GAG mimetic and control nanofibers in promoting angiogenesis and cardiac regeneration after MI in the pre-clinical small animal study. Both control and GAG mimetic nanofibers improved cardiac function in the short term while GAG mimetic nanofibers also increased vasculature via upregulation of VEGF-A and Ang1. This system serves as a new generation biomaterial for angiogenesis and tissue regeneration by avoiding the use of heparin and exogenous growth factors. While the injected scaffolds may provide localized regions for survival and organization of vascular cells, further studies are necessary to assess if it is possible for the scaffolds to be engineered to provide additional signals for in vivo recruitment and maturation of cardiomyocytes or cardiomyocyte progenitors as well. It is also crucial to determine whether these microenvironments will not be proarrhythmic, which will undermine the benefits of such treatment. The mechanism of differentiation induction through GAG mimetic nanofibers and affected signal pathways should also be deeply investigated. With these follow up studies, the technology of using selfassembled GAG mimetic peptide nanofibers in cardiac regeneration has a high potential of being translated into clinics.

\section{Author contributions}

R.A.J. and I.C.Y. contributed equally to this work. Authors declare that they have no competing interests.

\section{Funding}

This work was funded by TUBITAK, NRF R398000065592 and supported by TUBITAK-BIDEB 2210 fellowship. 


\section{Acknowledgements}

We would like to thank Gazi University, Ankara, for supplying cell line and $\mathrm{H}$. Ceylan for TEM imaging. This project was supported by the Scientific and Technological Research Council of Turkey (TUBITAK) and National Research Foundation of Singapore (NRF). A.B.T. acknowledges support from the Turkish Academy of Sciences Distinguished Young Scientist Award (TUBA-GEBIP).

\section{Appendix A. Supplementary data}

Supplementary data associated with this article can be found, in the online version, at http://dx.doi.org/10.1016/j.actbio.2017.06. 009.

\section{References}

[1] V.L. Roger, A.S. Go, D.M. Lloyd-Jones, R.J. Adams, J.D. Berry, T.M. Brown, M.R. Carnethon, S. Dai, G. de Simone, E.S. Ford, C.S. Fox, H.J. Fullerton, C. Gillespie, K. J. Greenlund, S.M. Hailpern, J.A. Heit, P.M. Ho, V.J. Howard, B.M. Kissela, S.J. Kittner, D.T. Lackland, J.H. Lichtman, L.D. Lisabeth, D.M. Makuc, G.M. Marcus, A. Marelli, D.B. Matchar, M.M. McDermott, J.B. Meigs, C.S. Moy, D. Mozaffarian, M. E. Mussolino, G. Nichol, N.P. Paynter, W.D. Rosamond, P.D. Sorlie, R.S. Stafford, T.N. Turan, M.B. Turner, N.D. Wong, J. Wylie-Rosett, Heart disease and stroke statistics-2011 update: a report from the American Heart Association, Circulation 123 (2011) e18-e209.

[2] J.A. Burdick, R.L. Mauck, J.H. Gorman, R.C. Gorman, Acellular biomaterials: an evolving alternative to cell-based therapies, Sci. Transl. Med. 5 (2013).

[3] M. Plotkin, S.R. Vaibavi, A.J. Rufaihah, V. Nithya, J. Wang, Y. Shachaf, T. Kofidis, D. Seliktar, The effect of matrix stiffness of injectable hydrogels on the preservation of cardiac function after a heart attack, Biomaterials 35 (2014) $1429-1438$.

[4] M.A. Laflamme, S. Zbinden, S.E. Epstein, C.E. Murry, Cell-based therapy for myocardial ischemia and infarction: pathophysiological mechanisms, Annu. Rev. Pathol. Mech. 2 (2007) 307-339.

[5] M. Simons, J.A. Ware, Therapeutic angiogenesis in cardiovascular disease, Nat. Rev. Drug Discovery 2 (2003) 863-871.

[6] R. Mammadov, B. Mammadov, S. Toksoz, B. Aydin, R. Yagci, A.B. Tekinay, M.O. Guler, Heparin mimetic peptide nanofibers promote angiogenesis, Biomacromolecules 12 (2011) 3508-3519.

[7] G. Courties, M.A. Moskowitz, M. Nahrendorf, The innate immune system after ischemic injury: lessons to be learned from the heart and brain, JAMA Neurol. 71 (2014) 233-236.

[8] Q. Sun, E.A. Silva, A. Wang, J.C. Fritton, D.J. Mooney, M.B. Schaffler, P.M. Grossman, S. Rajagopalan, Sustained release of multiple growth factors from injectable polymeric system as a novel therapeutic approach towards angiogenesis, Pharm. Res. 27 (2010) 264-271.

[9] S. Mohsin, J.C. Wu, M.A. Sussman, Predicting the future with stem cells, Circulation 129 (2014) 136-138.

[10] Z.J. Zhou, J.M. Wang, R.H. Cao, H. Morita, R. Soininen, K.M. Chan, B. Liu, Y.H. Cao, K. Tryggvason, Impaired angiogenesis, delayed wound healing and retarded tumor growth in perlecan heparan sulfate-deficient mice, Cancer Res. 64 (2004) 4699-4702.

[11] M. Simons, G.M. Rubanyi, Modern Concepts in Angiogenesis, Imperial College Press, 2007.

[12] K. Rajangam, H.A. Behanna, M.J. Hui, X.Q. Han, J.F. Hulvat, J.W. Lomasney, S.I. Stupp, Heparin binding nanostructures to promote growth of blood vessels, Nano Lett. 6 (2006) 2086-2090.

[13] K. Rajangam, M.S. Arnold, M.A. Rocco, S.I. Stupp, Peptide amphiphile nanostructure-heparin interactions and their relationship to bioactivity, Biomaterials 29 (2008) 3298-3305.

[14] R.O. Hynes, The extracellular matrix: not just pretty fibrils, Science 326 (2009) 1216-1219.

[15] W. Figg, J. Folkman, Angiogenesis: An Integrative Approach from Science to Medicine, Springer, 2008.

[16] T. Dvir, B.P. Timko, D.S. Kohane, R. Langer, Nanotechnological strategies for engineering complex tissues, Nat. Nanotechnol. 6 (2011) 13-22.

[17] L.W. Chow, R. Bitton, M.J. Webber, D. Carvajal, K.R. Shull, A.K. Sharma, S.I. Stupp, A bioactive self-assembled membrane to promote angiogenesis, Biomaterials 32 (2011) 1574-1582.

[18] L.W. Chow, L.J. Wang, D.B. Kaufman, S.I. Stupp, Self-assembling nanostructures to deliver angiogenic factors to pancreatic islets, Biomaterials 31 (2010) 61546161.

[19] M. Guerrini, D. Beccati, Z. Shriver, A. Naggi, K. Viswanathan, A. Bisio, I. Capila, J. C. Lansing, S. Guglieri, B. Fraser, A. Al-Hakim, N.S. Gunay, Z.Q. Zhang, L. Robinson, L. Buhse, M. Nasr, J. Woodcock, R. Langer, G. Venkataraman, R.J. Linhardt, B. Casu, G. Torri, R. Sasisekharan, Oversulfated chondroitin sulfate is a contaminant in heparin associated with adverse clinical events, Nat. Biotechnol. 26 (2008) 669-675.
[20] I.C. Yasa, N. Gunduz, M. Kilinc, M.O. Guler, A.B. Tekinay, Basal lamina mimetic nanofibrous peptide networks for skeletal myogenesis, Sci. Rep. 5 (2015) 16460.

[21] S. Ustun Yaylaci, M. Sardan Ekiz, E. Arslan, N. Can, E. Kilic, H. Ozkan, I Orujalipoor, S. Ide, A.B. Tekinay, M.O. Guler, Supramolecular GAG-like selfassembled glycopeptide nanofibers induce chondrogenesis and cartilage regeneration, Biomacromolecules 17 (2016) 679-689.

[22] G. Gulseren, I.C. Yasa, O. Ustahuseyin, E.D. Tekin, A.B. Tekinay, M.O. Guler, Alkaline phosphatase-mimicking peptide nanofibers for osteogenic differentiation, Biomacromolecules 16 (2015) 2198-2208.

[23] V.A. Kumar, N.L. Taylor, S. Shi, B.K. Wang, A.A. Jalan, M.K. Kang, N.C. Wickremasinghe, J.D. Hartgerink, Highly angiogenic peptide nanofibers, ACS Nano 9 (2015) 860-868.

[24] M.J. Webber, J. Tongers, C.J. Newcomb, K.-T. Marquardt, J. Bauersachs, D.W. Losordo, et al., Supramolecular nanostructures that mimic VEGF as a strategy for ischemic tissue repair, Proc. Natl. Acad. Sci. USA 108 (2011) 13438-13443.

[25] M.J. Webber, X. Han, S.N. Prasanna Murthy, K. Rajangam, S.I. Stupp, J.W. Lomasney, Capturing the stem cell paracrine effect using heparin-presenting nanofibres to treat cardiovascular diseases, J. Tissue Eng. Regener. Med. 4 (2010) 600-610.

[26] M.E. Davis, J.P.M. Motion, D.A. Narmoneva, T. Takahashi, D. Hakuno, R.D. Kamm, S. Zhang, R.T. Lee, Injectable self-assembling peptide nanofibers create intramyocardial microenvironments for endothelial cells, Circulation 111 (2005) 442-450.

[27] H.-D. Guo, G.-H. Cui, J.-J. Yang, C. Wang, J. Zhu, L.-S. Zhang, J. Jiang, S.-J. Shao, Sustained delivery of VEGF from designer self-assembling peptides improves cardiac function after myocardial infarction, Biochem. Biophys. Res. Commun. 424 (2012) 105-111.

[28] R. Mammadov, B. Mammadov, M.O. Guler, A.B. Tekinay, Growth factor binding on heparin mimetic peptide nanofibers, Biomacromolecules 13 (2012) 33113319.

[29] J.R. Bishop, M. Schuksz, J.D. Esko, Heparan sulphate proteoglycans fine-tune mammalian physiology, Nature 446 (2007) 1030-1037.

[30] E. Ling-Ling, Y.S. Zhao, X.M. Guo, C.Y. Wang, H. Jiang, J. Li, C.M. Duan, Y. Song, Enrichment of cardiomyocytes derived from mouse embryonic stem cells, J. Heart Lung Transpl. 25 (2006) 664-674.

[31] Z. Bin, L.G. Sheng, Z.C. Gang, J. Hong, C. Jun, Y. Bo, S. Hui, Efficient cardiomyocyte differentiation of embryonic stem cells by bone morphogenetic protein-2 combined with visceral endoderm-like cells, Cell Biol. Int. 30 (2006) 769-776.

[32] A. Chiavegato, S. Bollini, M. Pozzobon, A. Callegari, L. Gasparotto, J. Taiani, M. Piccoli, E. Lenzini, G. Gerosa, I. Vendramin, E. Cozzi, A. Angelini, L. Iop, G.F. Zanon, A. Atala, P. De Coppi, S. Sartore, Human amniotic fluid-derived stem cells are rejected after transplantation in the myocardium of normal, ischemic, immuno-suppressed or immuno-deficient rat, J. Mol. Cell. Cardiol. 42 (2007) 746-759.

[33] M.S. Parmacek, R.J. Solaro, Biology of the troponin complex in cardiac myocytes, Prog. Cardiovasc. Dis. 47 (2004) 159-176.

[34] Y.D. Lin, C.Y. Luo, Y.N. Hu, M.L. Yeh, Y.C. Hsueh, M.Y. Chang, D.C. Tsai, J.N. Wang, M.J. Tang, E.I.H. Wei, M.L. Springer, P.C.H. Hsieh, Instructive nanofiber scaffolds with VEGF create a microenvironment for arteriogenesis and cardiac repair, Sci. Transl. Med. 4 (2012) 146ra109.

[35] J.A. Matthews, G.E. Wnek, D.G. Simpson, G.L. Bowlin, Electrospinning of collagen nanofibers, Biomacromolecules 3 (2002) 232-238.

[36] M.F. Berry, A.J. Engler, Y.J. Woo, T.J. Pirolli, L.T. Bish, V. Jayasankar, et al., Mesenchymal stem cell injection after myocardial infarction improves myocardial compliance, Am. J. Physiol. Heart Circ. Physiol. 290 (2006) 21962203.

[37] S.B. Sonnenberg, A.A. Rane, C.J. Liu, N. Rao, G. Agmon, S. Suarez, R. Wang, A. Munoz, V. Bajaj, S. Zhang, R. Braden, P.J. Schup-Magoffin, O.L. Kwan, A.N. DeMaria, J.R. Cochran, K.L. Christman, Delivery of an engineered HGF fragment in an extracellular matrix-derived hydrogel prevents negative LV remodeling post-myocardial infarction, Biomaterials 45 (2015) 56-63.

[38] C.W. Cheng, L.D. Solorio, E. Alsberg, Decellularized tissue and cell-derived extracellular matrices as scaffolds for orthopaedic tissue engineering, Biotechnol. Adv. 32 (2014) 462-484.

[39] G. Uzunalli, Y. Tumtas, T. Delibasi, O. Yasa, S. Mercan, M.O. Guler, A.B. Tekinay Improving pancreatic islet in vitro functionality and transplantation efficiency by using heparin mimetic peptide nanofiber gels, Acta Biomater. 22 (2015) 818.

[40] S.M. Dallabrida, N. Ismail, J.R. Oberle, B.E. Himes, M.A. Rupnick, Angiopoietin-1 promotes cardiac and skeletal myocyte survival through integrins, Circ. Res. 96 (2005) e8-e24.

[41] J.-M. Tang, J.-N. Wang, L. Zhang, F. Zheng, J.-Y. Yang, X. Kong, L.-Y. Guo, L. Chen, Y.-Z. Huang, Y. Wan, S.-Y. Chen, VEGF/SDF-1 promotes cardiac stem cell mobilization and myocardial repair in the infarcted heart, Cardiovasc. Res. 91 (2011) 402-411.

[42] A.A. Rane, J.S. Chuang, A. Shah, D.P. Hu, N.D. Dalton, Y. Gu, K.L. Peterson, J.H. Omens, K.L. Christman, Increased infarct wall thickness by a bio-inert material is insufficient to prevent negative left ventricular remodeling after myocardial infarction, PLoS One 6 (2011) e21571.

[43] S.T. Wall, J.C. Walker, K.E. Healy, M.B. Ratcliffe, J.M. Guccione, Theoretical impact of the injection of material into the myocardium: a finite element model simulation, Circulation 114 (2006) 2627-2635. 